Journal of

Strategic Management

(JSM)

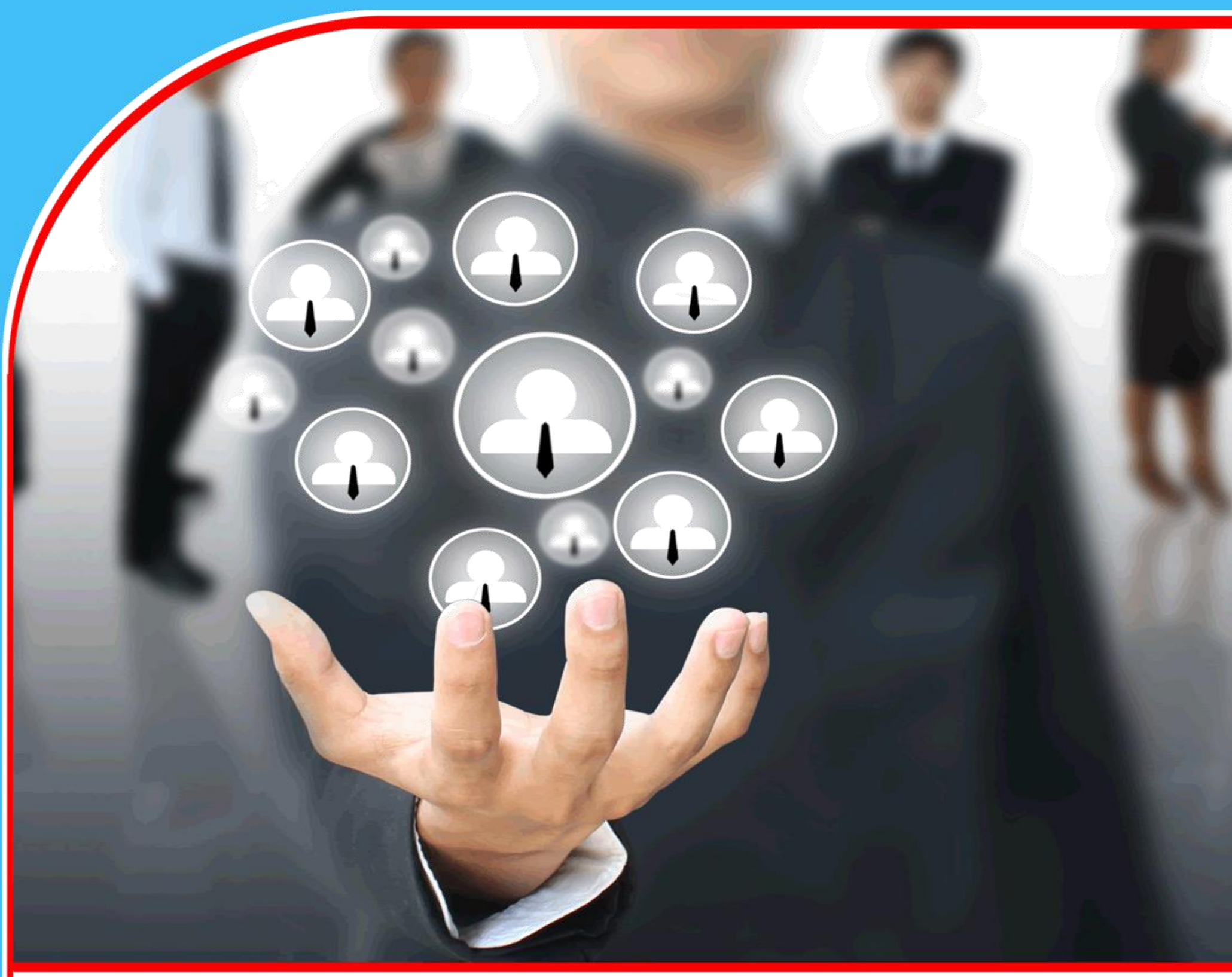

FACTORS INFLUENCING STRATEGIC RESPONSES TO EXTERNAL ENVIRONMENT BY DEPOSIT TAKING SACCOS IN NAIROBI COUNTY: A STUDY OF UNAITAS SACCO Salat Khalif Abdow and Dr. Kennedy Ogollah

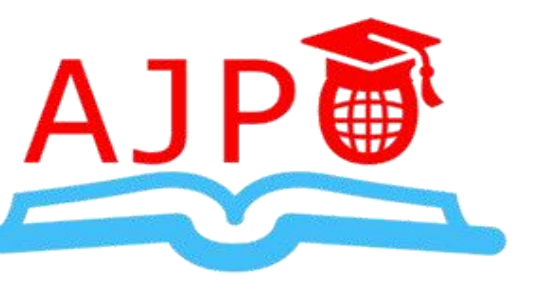




\title{
FACTORS INFLUENCING STRATEGIC RESPONSES TO EXTERNAL ENVIRONMENT BY DEPOSIT TAKING SACCOS IN NAIROBI COUNTY: A STUDY OF UNAITAS SACCO
}

\author{
1* Salat Khalif Abdow \\ ${ }^{1 *}$ Post graduate student, University of Nairobi \\ *Corresponding Author's Email: mkhalif33@gmail.com \\ 2* Dr. Kennedy Ogollah \\ Lecturer, University of Nairobi
}

\begin{abstract}
Purpose: The purpose of this study was to determine the factors influencing strategic responses to external environment by deposit taking SACCOS in Nairobi County: a study of Unaitas Sacco.

Methodology: The research adopted case study research design. The target population of the study was 11 directors and 600 employees of Unaitas Sacco. The sample size consisted of 61 (10\% of the target population) directors and employees of Unaitas Sacco. Stratified random sampling was used in the study to select the one director and the 60 employees of Unaitas Sacco. The study used primary data. The data collection instruments that were used in this study were the interview guide and questionnaire. The qualitative analysis was done using content analysis. Quantitative data analysis employed descriptive statistics and factor analysis. Descriptive statistics included frequencies, percentages, means and standard deviation. Results were presented in form of tables and charts. Particular statistics in factor analysis was scale plot and commonalities.
\end{abstract}

Results: The study found that reference to past strategy organization external dependence, consideration of level of risk and Organizational Culture greatly influences the choice of strategic response. In addition managerial competence, organizational structure and control processes, time available and availability of resources also greatly influence the choice of strategic response

Unique contribution to theory, practice and policy: The study recommends that Unaitas to invest more in the latest technology and start agency banking as a strategy of expanding its market share and product differentiation.

Key words: Strategic responses, external environment, organizational culture, managerial competence 


\subsection{INTRODUCTION}

\subsection{Background of the Study}

Strategic responses are the group of actions and decisions which leads to the formulation and execution of plans that help in achievement of objectives of firms. It therefore reacts to the happenings of a given environment of any organization. In the view of business environment becoming competitive, complex and turbulent, they respond to match with the environment (Njuguna, 2014). On the other hand external Environment can be considered as conditions of market, political issues and economic within national and local levels, aspects of demographic, among many forces coming from outside business environment that have an effect on the general success of that business (Ansoff, 2011). Therefore, strategy is vital to the adaptation of the changing business environment. According to Fahey and Narayanan (2006) businesses that learn to live with environmental uncertainty and incorporate it within their decision making processes are likely to succeed in the long run.

This study was anchored on the broad theoretical perspectives of the resource based Theory (RBT) theory and institutional theory. Resource based theory is considered relevant to this study since organizations require resources so that they can implement strategic responses. According to institutional theory competitive pressures of institutions apply tough impact, the managers' strategic decisions are both conformed to forces of institution, leading to legitimacy and isomorphism, as well as segregation, based on the firm's resource-based view, heterogeneity of resources increases the possibility of creating a competitive advantage (DiMaggio \& Powell, 1991).

Saccos are facing environmental challenges. According to Kaburi (2013) environmental conditions currently facing Saccos are different from the past decades. They have experienced tremendous technological changes, economic instability, cut throat competition, rapid sociological changes and governmental policies. These changes in the business environment determine the success and profitability of Saccos. Unaitas Sacco like many other Saccos has been experiencing turbulence in its business environment. To respond to the strong wind of change, the Sacco needs to devise ways to cope with the changeability and predictability of its business environment (Kaburi, 2013). According to Lwanga (2011) response strategies used in Sacco industry are important in helping an organization improve in performance and competitive edge. Some of the strategic responses by Saccos to changes in the environment include related and unrelated diversification, divesture, restructuring and rightsizing, Staff training and development, competitive appointment of senior staff, outsourcing some services, aggressive product promotion, internationalization, embracing technology, among others. There is therefore the need of new strategies that match the challenges from the environment and thus the current study sought to determine the factors influencing strategic responses to external environment by Unaitas Sacco.

\subsection{Research Problem}

Strategic responses are the group of actions and decisions which leads to the formulation and execution of plans that help in achievement of objectives of firms. It therefore reacts to the happenings of a given environment of any organization (Njuguna, 2014). According to Ansoff 
(2011) strategic response involves changes in the firm's strategic behaviors to ensure success in transforming future business environment.

The increasingly competitive environment poses challenges to organization with the last decade seeing a lot of changes in the economy of Kenya. Most of these changes have had mainly to do with liberalization, globalization, technological advancement and a more enlightened consumer. Organizations in general have to interact with their external environment as this is where they get their inputs and release their outputs after transformation (Mukiri, 2012). Consequently, they have to design strategies that allow for effective interaction with their external environment for the benefit of the organization. The strategic response to the organizations changes in the external environment may determine whether an organization survives. The external environment has a stake in the behavior and performance of an organization.

According to Kaburi (2013) environmental conditions currently facing Saccos are different from those of past decades. They have experienced tremendous technological changes, economic instability, cut throat competition, rapid sociological changes and governmental policies. These changes in the business environment determine the success and profitability of Saccos. Unaitas Sacco like many other Saccos has been experiencing turbulence changes in its business environment. These changes are strong and the Sacco cannot do a thing about them, it can only comply and thus to respond to the strong wind of change, the Sacco needs to devise ways to cope with the changeability and predictability of its business environment. There is therefore the need to study on factors influencing strategic responses to external environment by Unaitas Sacco.

\subsection{Objective of the Study}

The objective of the study was to determine the factors influencing strategic responses to external environment by deposit taking SACCOS in Nairobi County: a study of Unaitas Sacco.

\subsection{LITERATURE REVIEW}

\subsection{Theoretical Foundations of the Study}

\subsubsection{Resource Based Theory}

Penrose developed the Resource Based Theory (RBT) in year 1959 and recommended companies as groups of both human and physical resources combined in structure of organizations. RBT assumes that firms are bundles of resources (Werner felt, 1984). Olavarrieta (1996) observed that firm resources include the inputs which enable operations of firms as well as implementation of their strategies. According to this theory there are different classifications of resources. The summary of these factor are as follows: Input factors - this refers to common resources acquired from existing market. Input factors are related to logistics that include raw aspects like warehouse racking, forklift trucks, inventory as well as material packaging while raw skills is comprised of things like driving skills, picking skills, skills of computer operation and loading skills.

Barney (1991) observed that RBT strategic resources are specific resources of a firm which are imperfectly imitable, scarce and valuable and are able to generate rents. The importance of these resources is realized in inception and execution of strategies which can help in performance 
improvement, market opportunities exploitation or threats impending neutralization (Barney, 1995). They offer a provision of contribution with inconsistencies to value that is perceived by customers (Day, 1994).

The resource-based theory (RBT) of an organization has a provision to justify the significance of resources as well as effectiveness of HRM in order to maintatin competition sustainability (Barney \& Wright, 1997; Wright, Dunford, \& Snell, 2001). In particular, the RBT emphasizes the role of HR practices in influencing the human capital within organizations in a way that may lead to organizational success. Building upon the RBT, the nature of the relationship between strategic responses and external environment has become the focus of the strategic implementation field (Boselie et al., 2005). This theory was therefore relevant to this study since firms require resources to be able to implement strategies. These resources are inputs and they allow the firm to work and to implement its strategies.

\subsubsection{Institutional Theory}

Institutional theory was founded by DiMaggio and Powell (1991). This theory possesses rigid origins of sociology, its arguments is based on the idea that firms are rewarded socially through legitimate resources, as well as their market survival (DiMaggio \& Powell, 1991). This is an implication that the transfer of contextual ceremonies, symbols and values of the structures, practices as well as strategies of any given firm (Zucker, 1987).

Most institutions are vulnerable to coerciveness as well as normative forces in obtaining of the stakeholders' social support. In practice, institutional theory competitive pressures of institutions apply tough impact, the managers' strategic decisions are both conformed to forces of institution, leading to legitimacy and isomorphism, as well as segregation, based on the firm's resourcebased view, possibility of creating a competitive advantage is increased by resources' heterogeneity as well capabilities.

DiMaggio and Powell (1991) refer to institutional environments to the requirement of acceptance and conformity which enable institutions to become prisoners of the institutional isomorphism. This theory was therefore deemed relevant to this study since it puts to consideration the whole procedure of firm's structures like routines, schemes of work, norms, as well as rules which are put in place by authority in social behavior guidelines.

\subsection{Strategic Response and External Environment}

Kaburi (2013) conducted a study on strategic responses to the changes in the business environment by Unaitas Sacco society ltd, Kenya. The study adopted a content analysis method to analyze the data collected. The study found that Unaitas was affected by new technologies, high expectations from their clients, increased Government of Kenya supervision, weather fluctuations and increased competition. Unaitas responded by designing strategies to remain relevant, have a competitive edge and increase its market share. Some of the strategies that the Sacco devised are; marketing and advertisements, diversification, rebranding and partnership. Other strategies are; differentiation, cost leadership and diversification. The study recommended Unaitas to invest more in the latest technology and start agency banking as a strategy of expanding its market share and product differentiation. 
Mwithiga (2013) conducted a study on strategic responses adopted by Saccos to the Changing Operation Environment in the Kenyan Financial Sector. The study used both primary and secondary data. It used primary data collected using questionnaires to carry out the study. The study concluded that the Saccos use restructuring strategies most in responding to the changing operating environment most followed by Differentiation strategies, then diversification strategies while monitoring and evaluation strategies are the least used. The study recommends that the management should look for alternative sources of funding in order to overcome the challenges of finance related to restructuring strategy, economic recession and liquidity and solvency. The Saccos should also seek for ways of keeping overheads lower than others by use of knowledge from past experience. This study was conducted in Saccos with Front Office thus presenting a scope gap. The current study focused on Unaitas Sacco.

Mwangi (2014) conducted a study on strategic responses by Kenya national commission on human rights (KNCHR) to changes in the external environment. A case study approach was used, where face to face interviews were undertaken with eight respondents using an interview guide. The study found that KNCHR had experienced key changes in its macro environment touching on political, economic, socio-cultural, environmental and legal factors. This led to internal changes which largely impacted on KNCHR's structure, systems and processes. One of the key external changes is the new legislative frameworks such as the Constitution (2010) that led to creation of Article 59 Commissions. This resulted to increased competition, increased rivalry among the three commissions, funding constraints, high staff turnover among others. Further, the study found that in response to these changes, KNCHR had to adopt key strategic responses such as competitive, restructuring, organizational leadership, culture change and information technologies to survive. In conclusion the study established that an organization whether in public or private sector must constantly adjust to its environment so as to create a strategic fit for survival.

Muthaura (2011) found that major specific threats affecting stockbrokers include stiff competition for the few customers participating in the sector, CMA regulations, and negative publicity of stockbrokers due to poor corporate governance in the sector. Change in technology was another major challenge. On strategic responses applied to counter environmental threats, findings indicated that technological adoption, improving customer service and aligning with the demands of the regulators were the major responses. The following recommendations are made. First, CMA should introduce effective reforms incorporating views of all the stakeholders. Secondly, the political environment should be stabilized to attract foreign investors. Thirdly, NSE should put measures in place to ensure that the current trading system which runs through a wide area network is expanded to cover other major towns in Kenya. Lastly, the study recommends to all stockbrokers to curb insider trading, fraud and unauthorized trading in their companies.

Mukiri (2012) conducted a study on strategic responses by East African Breweries Limited to changes in the external environment. The study adopted a case study design. The researcher used content analysis to analyze the data through describing phenomena, classifying it and seeing how the concepts interconnect as was indicated by the respondents. The study findings indicated that EABL units have adopted two types of responses namely anticipatory approach which are 
driven by research on consumer and market trends and respective responses designed in order to maintain competitive advantage and stay ahead of the consumers and reactive approach which are driven by events happening in the market place that require responses ranging from competitor activities and changes in regulatory environment. The study therefore concludes that EABL continuously reviews/scans its environment and responds to the changes in the external environment based on potential impact of each change.

\subsection{METHODOLOGY}

The research adopted case study research design. The target population of the study was 11 directors and 600 employees of Unaitas Sacco. The sample size consisted of 61 (10\% of the target population) directors and employees of Unaitas Sacco. Stratified random sampling was used in the study to select the one director and the 60 employees of Unaitas Sacco. The study used primary data. The data collection instruments that were used in this study were the interview guide and questionnaire. The qualitative analysis was done using content analysis. Quantitative data analysis employed descriptive statistics and factor analysis. Descriptive statistics included frequencies, percentages, means and standard deviation. Results were presented in form of tables and charts. Particular statistics in factor analysis was scale plot and commonalities.

\subsection{RESULTS}

\subsection{Demographic Characteristics}

The results revealed that majority of the respondents who were $73 \%$ indicated that they were male while only $27 \%$ indicated that they were females. The results further indicated that $42 \%$ were between 41 - 50 years, $36 \%$ were between 31 - 40 years, $15 \%$ were less than 30 years while only $7 \%$ were above 50 years. In addition the results showed that majority of the respondents who were $53 \%$ indicated that they were undergraduate, $20 \%$ indicated post graduate, $16 \%$ indicated diploma while only $11 \%$ indicated certificate. The results further showed that majority of the respondents who were $53 \%$ indicated that they had worked for between $2-5$ years, $23 \%$ had worked for $6-10$ years, $13 \%$ had worked for less than 1 year, while only $11 \%$ had worked for above 10 years.

\subsection{Descriptive Statistics}

Respondents were asked to indicate to what extent the various factors influenced choice of strategic responses. Results are presented in Table 4.2. 
Table 1: Factors influencing choice of strategic responses

\begin{tabular}{|c|c|c|c|c|c|c|c|}
\hline Statement & $\begin{array}{l}\text { Not at } \\
\text { all }\end{array}$ & $\begin{array}{l}\text { To less } \\
\text { extent }\end{array}$ & $\begin{array}{l}\text { Moderat } \\
\text { e Extent }\end{array}$ & $\begin{array}{l}\text { To a } \\
\text { great } \\
\text { extent }\end{array}$ & $\begin{array}{l}\text { To a very } \\
\text { great } \\
\text { extent }\end{array}$ & $\begin{array}{l}\text { Mea } \\
\text { n }\end{array}$ & $\begin{array}{l}\text { Std. } \\
\text { Dev }\end{array}$ \\
\hline $\begin{array}{l}\text { Reference to past } \\
\text { strategy } \\
\text { Degree of the } \\
\text { organization }\end{array}$ & $5.50 \%$ & $18.20 \%$ & $14.50 \%$ & $43.60 \%$ & $18.20 \%$ & 3.51 & 1.15 \\
\hline External & & & & & & & \\
\hline Dependence & $1.80 \%$ & $14.50 \%$ & $7.30 \%$ & $47.30 \%$ & $29.10 \%$ & 3.87 & 1.05 \\
\hline $\begin{array}{l}\text { Consideration of } \\
\text { the level of risk } \\
\text { Organizational }\end{array}$ & $1.80 \%$ & $10.90 \%$ & $14.50 \%$ & $49.10 \%$ & $23.60 \%$ & 3.85 & 0.91 \\
\hline Culture & $9.10 \%$ & $9.10 \%$ & $5.50 \%$ & $49.10 \%$ & $27.30 \%$ & 3.76 & 1.21 \\
\hline $\begin{array}{l}\text { Managerial } \\
\text { competence }\end{array}$ & $3.60 \%$ & $18.20 \%$ & $1.80 \%$ & $41.80 \%$ & $34.50 \%$ & 3.85 & 1.19 \\
\hline $\begin{array}{l}\text { Organizational } \\
\text { structure and } \\
\text { control processes }\end{array}$ & $5.50 \%$ & $3.60 \%$ & $10.90 \%$ & $45.50 \%$ & $34.50 \%$ & 4 & 1.05 \\
\hline $\begin{array}{l}\text { The time available } \\
\text { for decision making } \\
\text { Availability of }\end{array}$ & $3.60 \%$ & $9.10 \%$ & $21.80 \%$ & $45.50 \%$ & $20.00 \%$ & 3.59 & 0.78 \\
\hline resources & $3.60 \%$ & $3.60 \%$ & $9.10 \%$ & $61.80 \%$ & $21.80 \%$ & 3.95 & 0.89 \\
\hline Total & & & & & & 3.86 & 1.03 \\
\hline
\end{tabular}

The results in table 4.2 revealed that majority of the respondents who were $61.8 \%$ indicated that reference to past strategy influenced their choice of strategic response to a great extent. The results further indicated that majority of the respondents who were $76.4 \%$ indicated that degree of the organization external dependence influenced their choice of strategic response to a great extent. The results further indicated that majority of the respondents who were $72.7 \%$ indicated that consideration of level of risk influenced their choice of strategic response to a great extent.

The results further revealed that majority of the respondents who were $76.4 \%$ indicated that Organizational Culture influenced their choice of strategic response to a great extent. The results further revealed that majority of the respondents who were $76.3 \%$ indicated that managerial competence influenced their choice of strategic response to a great extent. The results further revealed that majority of the respondents who were $80.0 \%$ indicated that organizational structure and control processes influenced their choice of strategic response to a great extent. The results further showed that majority of the respondents who were $65.5 \%$ indicated that the time available for decision making influenced their choice of strategic response to a great extent. The results further revealed that majority of the respondents who were $83.6 \%$ indicated that availability of resources influenced their choice of strategic response to a great extent. 
On an average likert scale the responses had an overall mean of 3.86 which indicated that the respondents indicated that the factors influenced choice of strategic response to a great extent. The standard deviation of 1.03 indicates that the responses were varied

The respondents were further asked to indicate whether Unaitas Sacco adopt differentiation strategies to cope with the external environment. Results are presented in Figure 1.

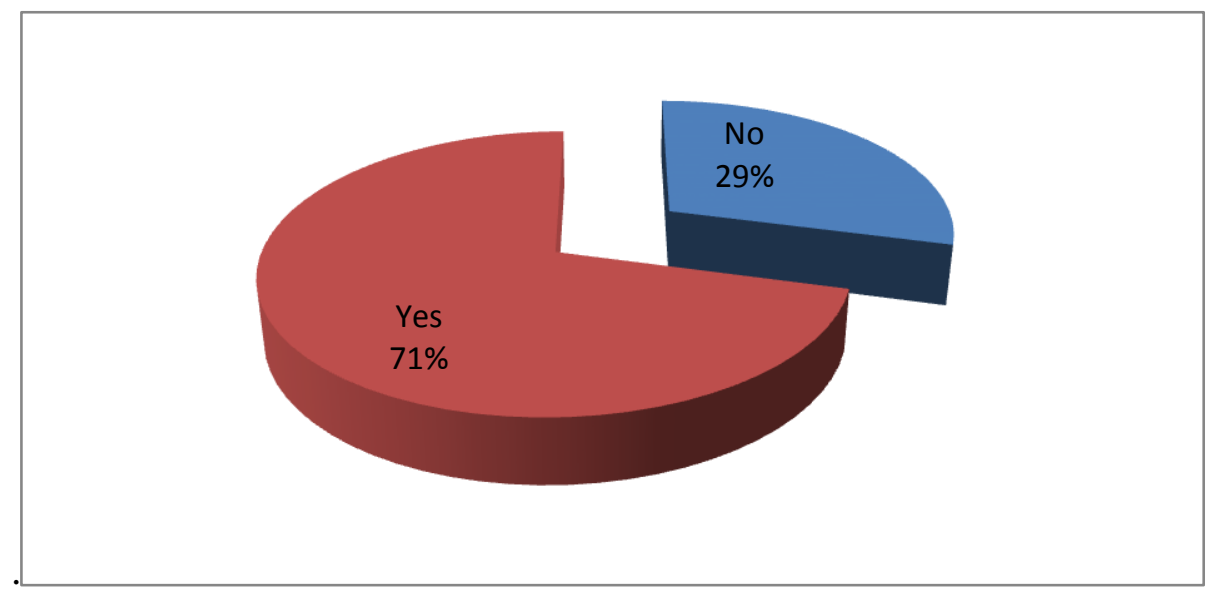

\section{Figure 1: Differentiation Strategies}

Majority of the respondents who were $71 \%$ indicated yes while only $29 \%$ indicated no. This implies that Unaitas Sacco adopt differentiation strategies to cope with the external environment. The respondents who indicated yes they were further asked to what extent Unaitas Sacco apply differentiation strategies as a competitive strategy. Figure 4.6 show the responses.

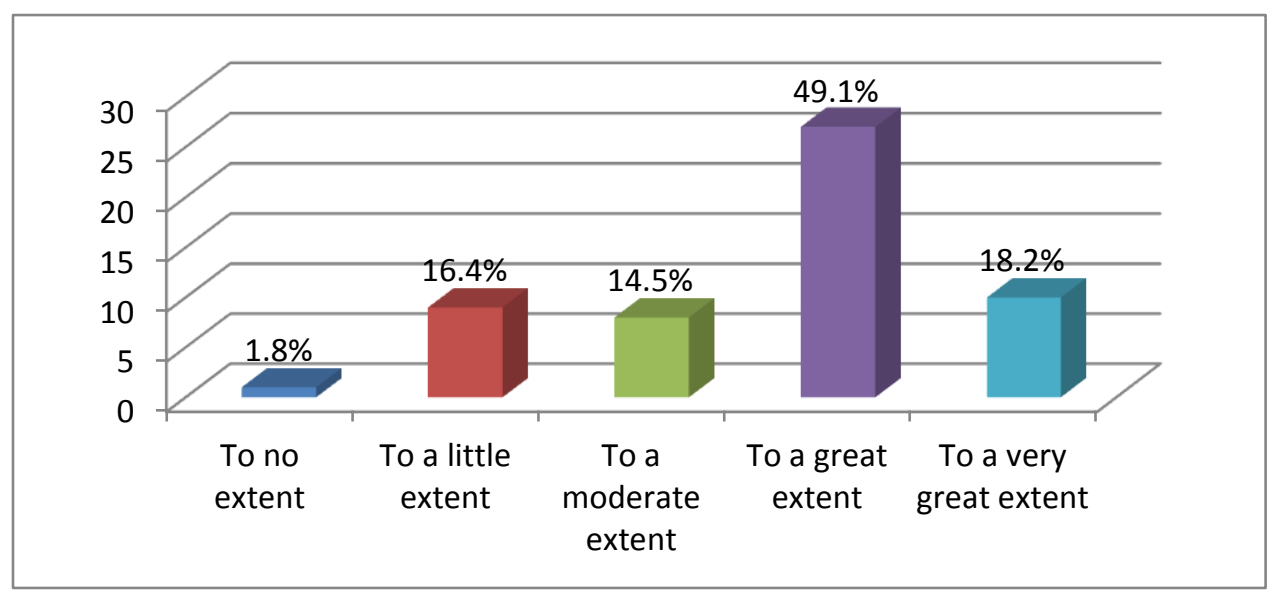

\section{Figure 2: Extent of Differentiation Strategies}

The respondents were further asked to indicate whether Unaitas Sacco adopts monitoring and evaluation strategies. Figure 3 indicate the responses. 


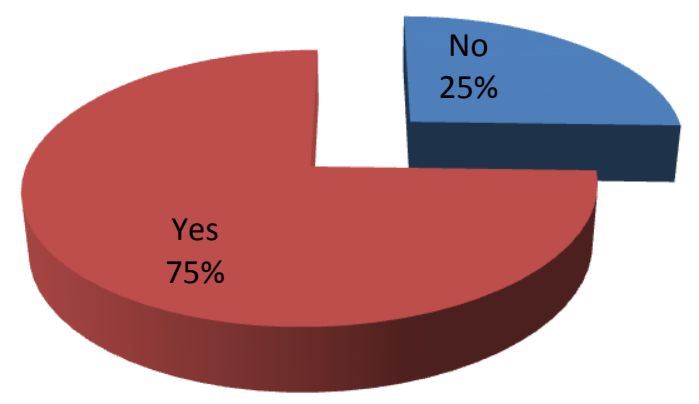

\section{Figure 3: Adoption of Monitoring and Evaluation Strategies}

Majority of the respondents who were $75 \%$ indicated yes while only $25 \%$ indicated no.

The respondents who indicated yes were asked to indicate to what extent Unaitas Sacco use monitoring and evaluation strategic responses in the changing external environment. The results are shown in Figure 4.

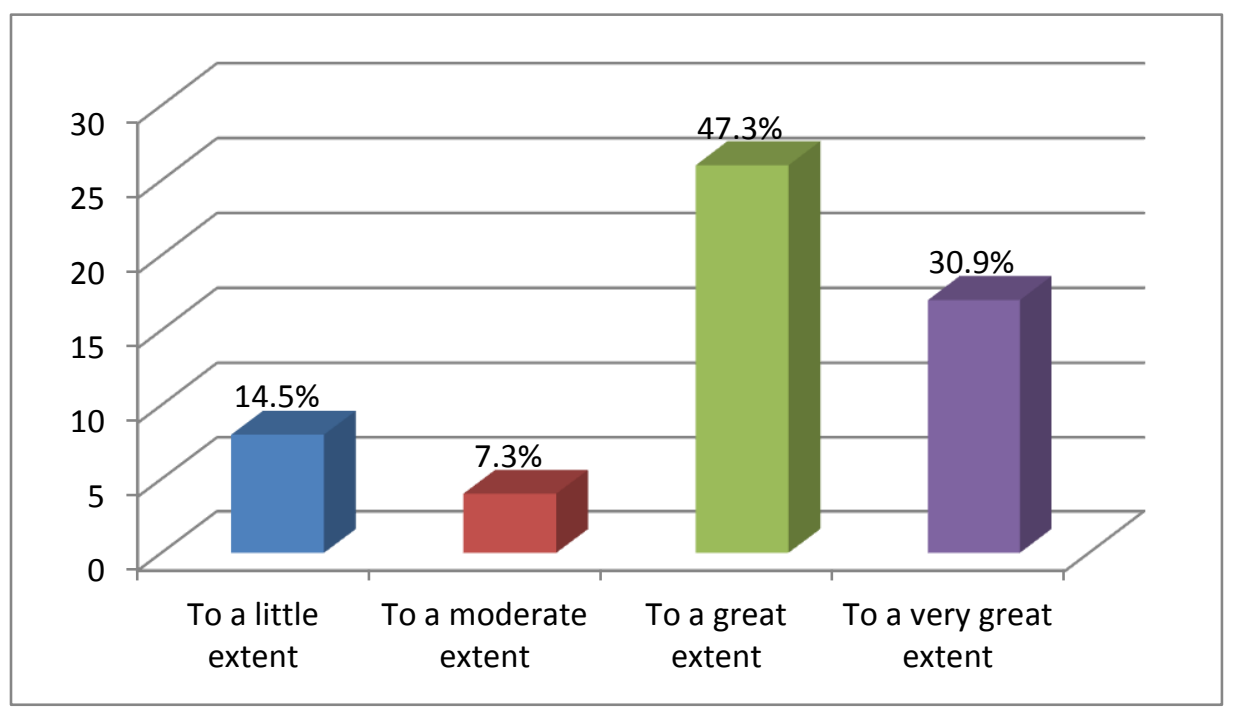

\section{Figure 4: Extent of Adoption of Monitoring and Evaluation Strategies}

The results revealed that $47.3 \%$ indicated that Unaitas Sacco use monitoring and evaluation strategic responses in the changing external environment to a great extent, $30.9 \%$ to a less extent, $14.5 \%$ to a little extent while only $7.3 \%$ indicated to a little extent.

The respondents were further asked to indicate to what extent the monitoring and evaluation strategies involve the following factors in responding to the changing external environment. The results are presented in Table 2. 
Table 2: Factors influencing monitoring and evaluation strategies

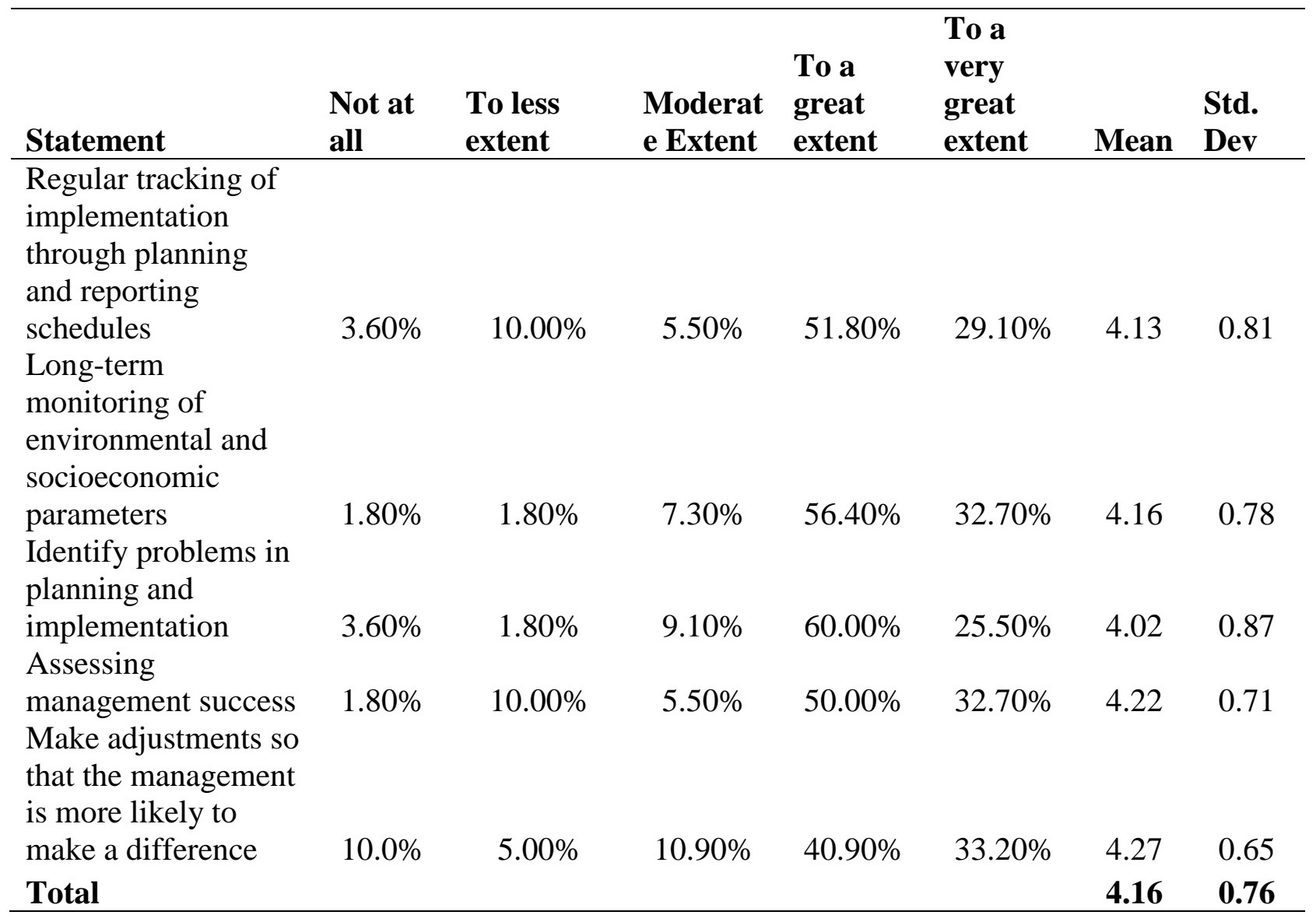

The results revealed that majority of the respondents who were $80.9 \%(51.8 \%+29.1 \%)$ indicated that they involve regular tracking of implementation through planning and reporting schedules to a great extent. The results further revealed that majority of the respondents who were $89.1 \%$ indicated that they involve long-term monitoring of environmental and socioeconomic parameters to a great extent. The results further showed that majority of the respondents who were $85.5 \%$ indicated that they involve identify problems in planning and implementation to a great extent. The results further revealed that $82.70 \%$ of the respondents indicated that they assess management success to a great extent.

The results further revealed that majority of the respondents who were $74.10 \%$ of the respondents indicated that they make adjustments so that the management is more likely to make a difference. On an average likert scale the responses had an overall mean of 4.16 which indicated that the respondents indicated that the factors influenced monitoring and evaluation strategies to a great extent. The standard deviation of 0.78 indicates that the responses were not varied. 


\subsection{Factor Analysis}

Factor analysis was also conducted so as to removes redundancy or duplication from a set of correlated variables if they happen to exist

\subsubsection{Kaiser-Meyer-Olkin Measure of Sampling Adequacy}

KMO test was first performed. Interpretive adjectives for the Kaiser-Meyer-Olkin Measure of Sampling Adequacy are: in the 0.90 as marvelous, in the 0.80 's as meritorious, in the 0.70 's as middling, in the 0.60's as mediocre, in the 0.50's as miserable, and below 0.50 as unacceptable. The value of the KMO Measure of Sampling Adequacy for this set of variables was 0.774, which would be labeled as 'middling'. Since the KMO Measure of Sampling Adequacy met the minimum criteria, and therefore we did not have a problem that requires the study to examine the Anti-Image Correlation Matrix.

Table 3: Kaiser-Meyer-Olkin Measure of Sampling Adequacy

\begin{tabular}{lcc}
\hline Kaiser-Meyer-Olkin Measure of Sampling Adequacy. & $\mathbf{0 . 7 7 4}$ \\
\hline Bartlett's Test of Sphericity & Approx. Chi-Square & 185.705 \\
& df & 28 \\
& Sig. & 0 \\
\hline
\end{tabular}

\subsubsection{Communalities}

When factor analysis on the factors no factor was dropped from further analysis because all the variables had a loading that was above 0.4. This was illustrated in Table 4.

Table 4: Communalities

\begin{tabular}{lrr}
\hline Communalities & Initial & Extraction \\
\hline Reference to past strategy & 1 & 0.622 \\
Degree of the organization External Dependence & 1 & 0.733 \\
Consideration of the level of risk & 1 & 0.815 \\
Organizational Culture & 1 & 0.622 \\
Managerial competence & 1 & 0.722 \\
Organizational structure and control processes & 1 & 0.46 \\
The time available for decision making & 1 & 0.697 \\
Availability of resources & 1 & 0.724 \\
\hline
\end{tabular}

\subsubsection{Total variance explained}

Rotation Sums of Squared Loadings values in this panel of the table 4.6 represent the distribution of the variance after the varimax rotation. Varimax rotation tries to maximize the variance of each of the factors, so the total amount of variance accounted for was redistributed over the two extracted factors.

This means that the two extracted factors out of the eight components explained $67.418 \%$ of the total variations. 
Table 5: Total variance explained

\begin{tabular}{lcccccc}
\hline $\begin{array}{l}\text { Compone } \\
\text { nt }\end{array}$ & \multicolumn{3}{c}{ Initial Eigenvalues } & & \multicolumn{3}{c}{ Extraction Sums of Squared Loadings } \\
\hline & \multicolumn{7}{c}{ \% of } & Cumulative & \% of & \\
& Total & Variance & $\%$ & Total & Variance & Cumulative \% \\
1 & 3.786 & 47.323 & 47.323 & 3.786 & 47.323 & 47.323 \\
2 & 1.608 & 20.095 & 67.418 & 1.608 & 20.095 & 67.418 \\
3 & 0.716 & 8.956 & 76.373 & & & \\
4 & 0.557 & 6.96 & 83.334 & & & \\
5 & 0.436 & 5.451 & 88.785 & & & \\
6 & 0.399 & 4.992 & 93.777 & & & \\
7 & 0.295 & 3.692 & 97.469 & & & \\
8 & 0.202 & 2.531 & 100 & & & \\
Extraction Method: Principal Component Analysis.
\end{tabular}

The scree plot graphs the eigenvalue against the factor number. From the second factor on, the line is almost flat, meaning the each successive factor is accounting for smaller and smaller amounts of the total variance

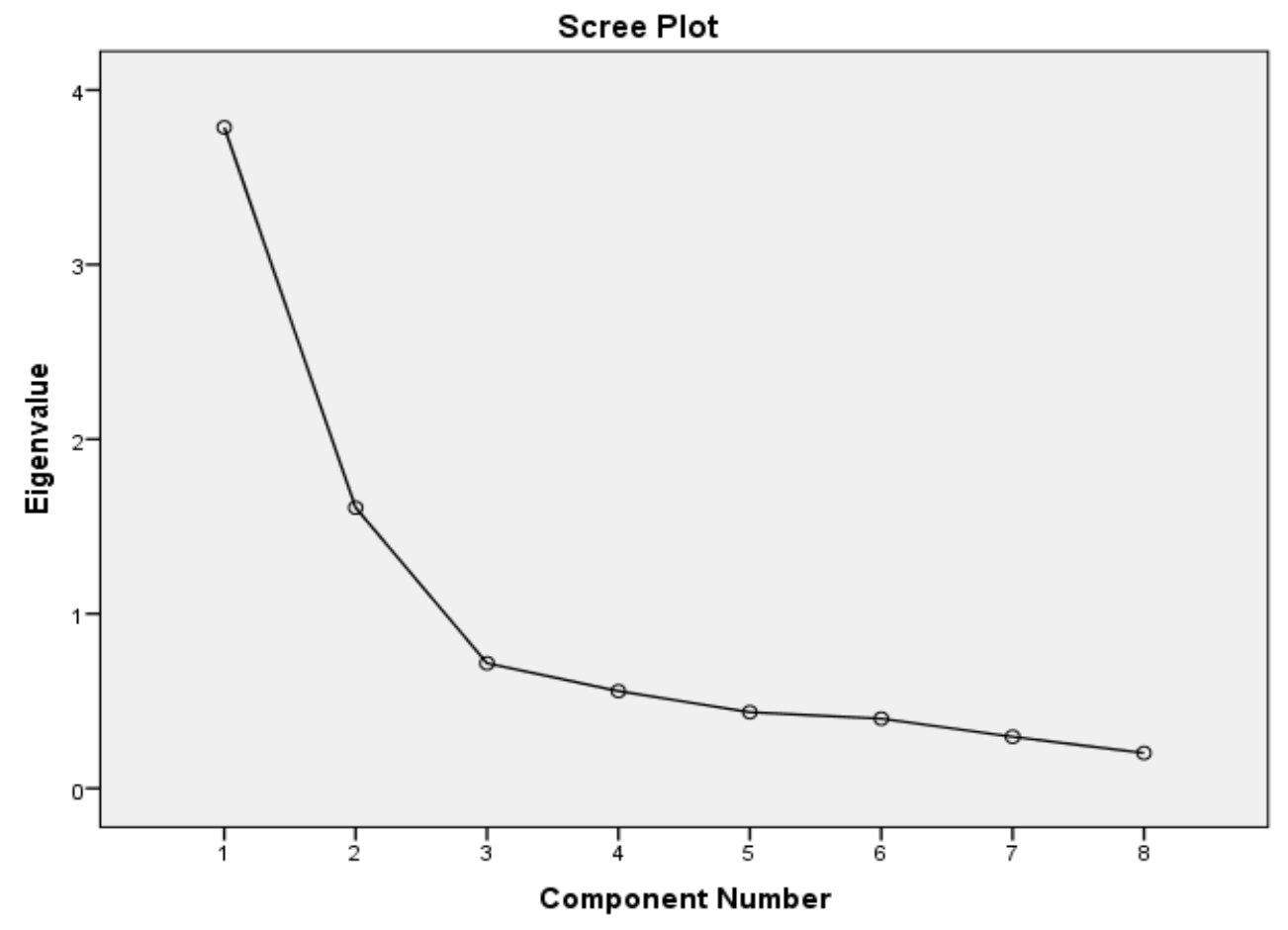




\section{Figure 5: Scree Plot}

\subsubsection{Component Matrix before rotation}

Table 6 below shows the component matrix before rotation.

Table 6: Component Matrix before Rotation

\begin{tabular}{lrr}
\hline & $\mathbf{1}$ & $\mathbf{2}$ \\
\hline Reference to past strategy & 0.849 & 0.016 \\
Degree of the organization External Dependence & -0.078 & 0.852 \\
Consideration of the level of risk & 0.202 & 0.88 \\
Organizational Culture & 0.78 & 0.113 \\
Managerial competence & 0.849 & 0.016 \\
Organizational structure and control processes & 0.651 & -0.189 \\
The time available for decision making & 0.804 & -0.226 \\
Availability of resources & 0.847 & 0.082 \\
\hline
\end{tabular}

\subsubsection{Rotated Component Matrix}

Table 7 contains the rotated factor loadings (factor pattern matrix), which represent both how the variables are weighted for each factor but also the correlation between the variables and the factor. The columns under this heading are the rotated factors that have been extracted. Two factors were extracted. These were renamed as shown in the last column guided by the values shaded.

Table 7: Rotated Component Matrix

\begin{tabular}{lccc}
\hline Factor & $\mathbf{1}$ & $\mathbf{2}$ & New Classification \\
\hline Reference to past strategy & 0.849 & 0.016 & Internal factor \\
The time available for decision making & 0.847 & 0.082 & Internal factor \\
Availability of Resources & 0.804 & -0.226 & Internal factor \\
Organizational Culture & 0.788 & 0.028 & Internal factor \\
Managerial competence & 0.78 & 0.113 & Internal factor \\
Organizational structure and control processes & 0.651 & -0.189 & Internal factor \\
Degree of the organization External Dependence & 0.202 & 0.88 & External factor \\
Consideration of the level of risk & -0.078 & 0.852 & External factor \\
\hline
\end{tabular}

\subsection{Content Analysis}

The respondent was asked to respond to the question on whether Unaitas has been influenced by changes in its business environment. The respondent said yes. The respondent explained that they have been greatly affected by changes in technology. This was supported by the following responses:

Respondent 'yes. new technology have greatly affected us' 
The respondent was asked to respond on the question of whether the Government of Kenya play any role in operations such as registration and regulation. The respondent said yes. The respondent said that the Government of Kenya plays a role in the Unaitas operations due to the taxes that they charge. This was supported by the following responses:

\section{Respondent 'yes. taxes affect our operations'}

The respondent was asked to respond to the question onwhether entrance of new Saccos in the market poses threats to existence and profitability of Unaitas. The respondent said yes.

The respondent further said that entrance of new Saccos for example Kenya highlands Sacco which has been having been giving low interest to customers. This was supported by the following responses:

'Respondent 'yes some Sacco's like Kenya highlands Sacco have been posing a threat by giving low interest rates to customers'

The respondent was also asked to indicate how they compete with other Saccos for market share. The respondent indicated that they have adopted competitive strategies as a way of gaining competitive advantage in the industry

Respondent 'we have adopted competitive strategies as a way of gaining competitive advantage in the industry'

The respondent was also asked to state the strategies they have adopted in response to competition from other Saccos. The respondent indicated that they have adopted product differentiation strategies, cost strategies and focus strategies.

\section{Respondents 'we have adopted product differentiation strategies, cost strategies and focus strategies.'}

\subsection{Discussions}

From the results the study found that majority of the respondents indicated that reference to past strategy influenced their choice of strategic response to a great extent. The results further indicated that majority of the respondents indicated that degree of the organization external dependence influenced their choice of strategic response to a great extent.

The results further indicated that majority of the respondents indicated that consideration of level of risk influenced their choice of strategic response to a great extent. The results further revealed that majority of the respondents indicated that Organizational Culture influenced their choice of strategic response to a great extent. These results agree with that of Were (2007) who found that organizational culture, and consideration of the level of risk influence their strategic responses.

The results further revealed that majority of the respondents indicated that managerial competence influenced their choice of strategic response to a great extent. The results further revealed that majority of the respondents indicated that organizational structure and control processes influenced their choice of strategic response to a great extent. The results further 
showed that majority of the respondents indicated that the time available for decision making influenced their choice of strategic response to a great extent. The results further revealed that majority of the respondents indicated that availability of resources influenced their choice of strategic response to a great extent. These findings agree with that of Mwithiga (2013) who argued that management should look for alternative sources of funding in order to overcome the challenges of finance related to restructuring strategy, economic recession and liquidity and solvency.

The results further revealed that majority of the respondents indicated that they involve regular tracking of implementation through planning and reporting schedules to a great extent. The results further revealed that majority of the respondents indicated that they involve long-term monitoring of environmental and socioeconomic parameters to a great extent. These findings agree with that of Mwithiga (2013) who concluded that that the Saccos greatly use monitoring and evaluation strategies.

The results further showed that majority of the respondents indicated that they involve identifying problems in planning and implementation to a great extent. The results further revealed that majority of the respondents indicated that they assess management success to a great extent. The results further revealed that majority of the respondents of the respondents indicated that they make adjustments so that the management is more likely to make a difference.

\subsection{CONCLUSIONS AND RECOMMENDATIONS}

\subsection{Conclusions}

The study concluded that reference to past strategy organization external dependence, consideration of level of risk and Organizational Culture greatly influences the choice of strategic response. In addition managerial competence, organizational structure and control processes, time available and availability of resources also greatly influence the choice of strategic response. The study also concludes that Unaitas Sacco continuously reviews/scans its environment and responds to the changes in the external environment based on potential impact of each change. The Sacco has devised ways to cope with the changeability and predictability of its business environment. This has enhanced the performance of the Sacco and hence the profitability.

\subsection{Recommendations}

The study recommended Unaitas to invest more in the latest technology. It should also start agency banking. This will act as a strategy of expanding its market share, product differentiation and diversification.

The study also recommends that the management of Unaitas Sacco should ensure that the employees are competent so as to cope with the competitive environment. In addition Unaitas Sacco should adopt product differentiation strategies, cost strategies and focus strategies so as to cope with the competitive environment. The study also recommends that the management of Unaitas Sacco should look for alternative sources of funding in order to overcome the challenges of finance related to restructuring strategy, economic recession and liquidity and solvency. 
The study recommends that Unaitas Sacco should adopt collaboration and strategic alliances with other Saccos, competitive action to introduce new products and services among other measures to mitigate the challenges from the external environment. It should design strategies to remain relevant, have a competitive edge and therefore increase its market share. This will create a strategic fit for survival.

\section{REFERENCES}

Njuguna, A. N. (2014). Strategic Responses and External Environmental Challenges By International Committee Of The Red Cross In Nairobi(Unpublished MBA Thesis. University of Nairobi, Kenya)

Ansoff, H.I. and McDonnel, E.J. (2010).Implanting Strategic Management. New York: Prentice Hall.

Kaburi, M. P. (2013). Strategic responses to the changes in the business environment by unaitassacco society ltd, Kenya (Unpublished MBA Thesis, University of Nairobi, Kenya)

Lwanga, C. M. (2011).Strategic responses of Saccos to changing competitive business environment: a study of Kussco affiliated Saccos in Nairobi county(Unpublished MBA Thesis, University of Nairobi, Kenya)

Fahey, L. and Narayanan, V. (2006).Macro environmental Analysis for Strategic Management. Thomson Learning, Florence, KY, (pp.23-30).

Njuguna, A. N. (2014). Strategic Responses and External Environmental Challenges By International Committee Of The Red Cross In Nairobi(Unpublished MBA Thesis. University of Nairobi, Kenya)

Kaburi, M. P. (2013). Strategic responses to the changes in the business environment by unaitassacco society ltd, Kenya (Unpublished MBA Thesis, University of Nairobi, Kenya) 